\title{
The Application of Augmented Reality for Intervention to People with Autism Spectrum Disorders
}

\author{
MSc Persefoni Karamanoli ${ }^{1}$, Prof Avgoustos Tsinakos ${ }^{1}$ \\ Prof Charalampos Karagiannidis ${ }^{2}$ \\ ${ }^{1}$ Eastern Macedonia and Thrace Institute of Technology (EMATTECH), Kavala, Greece \\ ${ }^{2}$ University of Thessaly, Volos, Greece
}

\begin{abstract}
For people with autism spectrum disorders (ASD), the application of a technological tool, like augmented reality $(A R)$, in their intervention programs is a new and still unexplored option. This literature review examines studies that have used AR for direct intervention to people with ASD. It must be mentioned though that since the incorporation of $A R$ in intervention programs is in its infancy, this literature review will only provide a review of the few initial studies that exist and also some proposals for future development and evaluation.
\end{abstract}

\section{Introduction}

Modern educational systems have to deal with the increasing number of students diagnosed with Autism Spectrum Disorders (ASD) (Escobedo et al., 2012). The term ASD refers to a permanent disability which is usually identified in childhood and affects major developmental aspects, like communication and interaction with other people (Autism.Society). According to Wang and Cloud the three basic aspects that people with ASD present difficulties are: a) reciprocal social engagement, b) reciprocal communication and c) flexible regulation of self-behaviour and interest (Mintz, 2013; Wing \& Gould, 1979).

The abovementioned lead to the conclusions that traditional teaching methods, such as face-to-face instructions where everything is controlled by the teacher, fail to offer the proper possibilities for enhancing the interests and abilities of students with ASD (Nincarean, Alia, Halim, \& Rahman, 2013; Olney, 2000; Tomi \& Rambli, 2013). One of the most recent technological advances that starts to be used for providing intervention to individuals with ASD is Augmented Reality (AR) (Wainer \& Ingersoll, 2011), a technology that enables users to see and experience the real world mixed with various virtual objects, without losing the sense of reality (Cuendet, Bonnard, Do-Lenh, \& Dillenbourg, 2013; Fonseca, Martí, Redondo, Navarro, \& Sánchez, 2014). AR as a technological tool, can be, as Vygotsky and Luria quoted, a "compensatory mechanism" and a psychological tool that can "transform ...natural abilities into higher mental functions..." (Farr, Yuill, \& Hinske, 2012). Researchers have started to apply AR to the education and training of students with ASD. However, despite the fact that AR tools are now affordable, their deployment in real conditions is non-existent (Prieto, Wen, Caballero, \& Dillenbourg, 2014). This literature review will examine studies that have used AR for direct intervention on people with ASD. It must be mentioned though that since the incorporation of AR in education (both regular and special) is in its infancy, this literature review will provide a review of the few initial studies that exist. 2

\subsection{Autism Spectrum Disorders (ASD)}

\section{Definitions}

According to the American Psychiatric Association "ASD is a complex developmental disorder that can cause problems with thinking, feeling language and the ability to relate to others. It is neurological disorder, which means it affects the functioning of the brain, The effects of autism and the severity of symptoms are different in its person"(Benson, 2016). As a disability, ASD is a lifelong disorder that can be diagnosed in childhood. It is estimated that 1:68 children in the USA are born with ASD and also it is 3-4 times most common in boys (Autism Society).

There are three types of ASD, Autistic Disorder, Asperger's Disorder and Atypical Autism. While Asperger's Disorder and Atypical Autism constitute different categories, they present similar characteristics with Autistic Disorder. This is why only the basic characteristics of Autistic Disorder will be presented (Benson, 2016; Olney, 2000).

$\square$ Communication problems: Difficulty in using and/or understand language. Also, it may lead to limited topic areas, repetition of phrases and very limited speech.

Difficulty in relationships: Like relating/interacting with people, making friends, understanding facial expressions and making eye-contact. 
Repetitive moves or behaviors: For example, hand flapping.

Also, it should be noted that people with ASD may have normal cognitive skills, while other do not. In other words, ASD refers from person to person in severity and symptoms (Krasny, Williams, Provencal, \& Ozonoff, 2003).

\subsection{Augmented Reality (AR)}

Many definitions may be given for Augmented Reality (AR), but according to Cuendet "Augmented reality refers to technologies that project digital materials onto real world objects. This definition suits a large spectrum of technologies that range from a pure virtual environment to the real environment."(Cuendet et al., 2013)

AR systems/applications enable users to sense properties about the real world, process in real time, use visual, audio, and haptic means overlaid on the real world and the use of mobile or wearable devices (Roesner, Denning, Newell, Kohno, \& Calo, 2014). Another important fact related to AR is its origin, as it is considered to be the evolution of Virtual Reality (VR). It could be pointed that the basic difference between VR and AR is the fact that VR does not use at all the camera field, something that AR is based on (Sood, 2012). Finally, AR is one of the most promising technologies for educational applications, and this is why researchers all around the world are experimenting on how its application could reach its full potential on students' progress. Its capability to combine the real world with virtual content presents new possibilities for learning and enhances the quality of the provided education, something that could be proved extremely beneficial for students with ASD (Karamanoli \& Tsinakos, 2015).

\section{Literature Review Method}

Articles examining the use of AR for individuals with ASD were collected mostly through the Science Direct, ieee Explore, PsychINFO and PubMed databases. Search terms included ASD, Autistic Spectrum Disorders, Autism, Asperger's Symptom along with the term Augmented Reality. Also, some articles were found from the list pf references from the abovementioned articles. The selected articles fulfill the following criteria:
$\square$ Are focused on ASD,
$\neg$ Use AR systems,
Describe the AR system they propose,
Were published between 2012-2016

\section{Results}

In total, 10 studies related to the use of AR for teaching mainly social skills, emotion recognition and other skills like cognitive activities and also facilitation of teachers of children with ASD, were selected for this literature review. These articles ca be found in Table 1 along with information. It must be mentioned that due to the fact that this field is new and few studies have been undertaken the number of the presented articles is quite small. Also, the main focus of the study is from 2012-2016 since this is the state-of-art in this field.

Table 1: The reviewed studies

\begin{tabular}{|c|c|c|c|c|c|c|c|}
\hline Authors & Year & $\mathbf{N}$ & Age & Participants & Application & Skills & Results \\
\hline $\begin{array}{l}\text { Escobedo, } \\
\text { Nguyen et al. }\end{array}$ & 2012 & 15 & $\begin{array}{l}8-12 \\
\text { years }\end{array}$ & $\begin{array}{l}3 \text { with ASD } \\
12 \text { typically } \\
\text { developed }\end{array}$ & $\begin{array}{l}\text { Mobile assistive } \\
\text { application } \\
(\mathrm{MOSOCO})\end{array}$ & Social skills & $\begin{array}{l}\text { MOSOCO } \\
\text { reduced social } \\
\text { missteps by } 56 \% \\
\text { and behavioral } \\
\text { issues by } 98 \% \text { to } \\
\text { children with } \\
\text { ASD. }\end{array}$ \\
\hline $\begin{array}{l}\text { Bhatt, De } \\
\text { Leon \& Al } \\
\text { Jumaily }\end{array}$ & 2014 & 4 & $\begin{array}{l}10-15 \\
\text { years }\end{array}$ & $\begin{array}{l}\text { Typically } \\
\text { developed }\end{array}$ & Two AR games & $\begin{array}{l}\text { Social } \\
\text { interaction } \\
\text { \&Hand-eye } \\
\text { coordination }\end{array}$ & $\begin{array}{l}\text { The games have } \\
\text { the potential to } \\
\text { improve the } \\
\text { social skills and } \\
\text { hand-eye } \\
\text { coordination of } \\
\text { children but } \\
\text { further research } \\
\text { is mandatory in } \\
\text { order to extend } \\
\text { these } \\
\text { assumptions to } \\
\text { children with } \\
\text { ASD. }\end{array}$ \\
\hline
\end{tabular}


The application of augmented reality for intervention to people with autism spectrum disorders

\begin{tabular}{|c|c|c|c|c|c|c|c|}
\hline $\begin{array}{l}\text { Chen, Lee \& } \\
\text { Lin }\end{array}$ & 2015 & 3 & $\begin{array}{l}10-13 \\
\text { years }\end{array}$ & ASD & $\begin{array}{l}\text { AR-based self- } \\
\text { facial model } \\
\text { (ARSFM) }\end{array}$ & $\begin{array}{l}\text { Emotion } \\
\text { recognition }\end{array}$ & $\begin{array}{l}\text { ARSFM can } \\
\text { facilitate the } \\
\text { emotional } \\
\text { recognition } \\
\text { teaching of } \\
\text { children with } \\
\text { ASD. } \\
\text { The correct } \\
\text { assessment rates } \\
\text { of all participants } \\
\text { raised } \\
\text { significantly. } \\
\text { They stayed more } \\
\text { focused during } \\
\text { therapy. }\end{array}$ \\
\hline \multirow[t]{2}{*}{$\begin{array}{l}\text { Chen, Lee \& } \\
\text { Lin }\end{array}$} & 2016 & 6 & $\begin{array}{l}11-13 \\
\text { years }\end{array}$ & ASD & $\begin{array}{l}\text { AR video- } \\
\text { modeling } \\
\text { storybook } \\
\text { (ARVMS) }\end{array}$ & $\begin{array}{l}\text { Emotion and } \\
\text { facial } \\
\text { expression } \\
\text { recognition }\end{array}$ & $\begin{array}{l}\text { Participants } \\
\text { presented } \\
\text { significant raising } \\
\text { in their scores in } \\
\text { understanding the }\end{array}$ \\
\hline & & & & & & & $\begin{array}{l}\text { emotions } \\
\text { presented in the } \\
\text { storybook. }\end{array}$ \\
\hline $\begin{array}{l}\text { Brandão, } \\
\text { Cunha, } \\
\text { Vasconcelos, } \\
\text { Carvalho, \& } \\
\text { Soares }\end{array}$ & 2015 & - & - & - & AR GameBook & - & - \\
\hline $\begin{array}{l}\text { Casas, } \\
\text { Herrera, } \\
\text { Coma \& } \\
\text { Fernadez }\end{array}$ & 2012 & 27 & $\begin{array}{l}3-4 \\
\text { years }\end{array}$ & $\begin{array}{l}5 \text { with ASD } \\
22 \text { typically } \\
\text { developed }\end{array}$ & $\begin{array}{l}\text { Augmented } \\
\text { mirror, where } \\
\text { users can see } \\
\text { themselves } \\
\text { augmented with } \\
\text { virtual objects. }\end{array}$ & $\begin{array}{l}\text { Developmental } \\
\text { abilities }\end{array}$ & $\begin{array}{l}\text { The AR system } \\
\text { can be used from } \\
\text { children with } \\
\text { ASD, but further } \\
\text { research should } \\
\text { be done. }\end{array}$ \\
\hline $\begin{array}{l}\text { Bai, } \\
\text { Blackwell \& } \\
\text { Coulouris }\end{array}$ & 2013 & 16 & $\begin{array}{l}4-7 \\
\text { years } \\
4-5 \\
\text { years }\end{array}$ & $\begin{array}{l}12 \text { with ASD } \\
4 \text { typically } \\
\text { developed }\end{array}$ & $\begin{array}{l}\text { System based } \\
\text { on the metaphor } \\
\text { of a mirrored } \\
\text { view of reality } \\
\text { enriched with } \\
\text { AR } \\
\text { augmentations. }\end{array}$ & Pretend play & $\begin{array}{l}\text { The frequency of } \\
\text { pretend play, } \\
\text { while using the } \\
\text { system, was } \\
\text { higher, while } \\
\text { constructive play } \\
\text { was more } \\
\text { frequent in the } \\
\text { non-AR } \\
\text { condition. The } \\
\text { same results } \\
\text { applied for the }\end{array}$ \\
\hline $\begin{array}{l}\text { Escobedo \& } \\
\text { Tentori }\end{array}$ & 2014 & 21 & $\begin{array}{l}3-7 \\
\text { years }\end{array}$ & $\begin{array}{l}14 \text { with ASD } \\
7 \text { teachers }\end{array}$ & MOBIS & $\begin{array}{l}\text { Teachers' } \\
\text { application }\end{array}$ & $\begin{array}{l}\text { Positive impact of } \\
\text { MOBIS on the } \\
\text { workload and } \\
\text { burden of teachers, } \\
\text { since it reduced the } \\
\text { time they spend for } \\
\text { giving prompts } \\
\text { taking notes } \\
\text { and also they were } \\
\text { able to teach more } \\
\text { than one students } \\
\text { per session }\end{array}$ \\
\hline $\begin{array}{l}\text { Tobar-Muñoz, } \\
\text { Baldiris \& } \\
\text { Fabrefat }\end{array}$ & 2014 & 20 & - & $\begin{array}{l}2 \text { with ASDs } \\
14 \text { with other } \\
\text { special needs } \\
4 \text { typically } \\
\text { developed }\end{array}$ & $\begin{array}{l}\text { AR-Enriched } \\
\text { Videogame }\end{array}$ & Math skills & $\begin{array}{l}\text { Students with } \\
\text { special needs } \\
\text { needed more time } \\
\text { than the typically } \\
\text { developed, but their } \\
\text { scores and } \\
\text { performance was } \\
\text { similar. Also, the } \\
\text { application } \\
\text { achieves the } \\
\text { inclusion of all } \\
\text { children into the } \\
\text { educational } \\
\text { procedure. }\end{array}$ \\
\hline
\end{tabular}


The application of augmented reality for intervention to people with autism spectrum disorders

\begin{tabular}{|c|c|c|c|c|c|c|c|}
\hline $\begin{array}{l}\text { Almeida da } \\
\text { Silva, } \\
\text { Fernandes \& } \\
\text { Grohmann }\end{array}$ & 2015 & 4 & $\begin{array}{l}6-10 \\
\text { years }\end{array}$ & 4 with ASD & STAR & $\begin{array}{l}\text { Therapists' and } \\
\text { parents' } \\
\text { application }\end{array}$ & $\begin{array}{l}\text { Students remained } \\
\text { focus during the } \\
\text { various activities, } \\
\text { completed them } \\
\text { correctly and } \\
\text { acquired new } \\
\text { vocabulary. There } \\
\text { were issues related }\end{array}$ \\
\hline & & & & & & & $\begin{array}{l}\text { to the overall } \\
\text { attention of the } \\
\text { students and the } \\
\text { eye contact } \\
\text { frequency }\end{array}$ \\
\hline & & & & & & & $\begin{array}{l}\text { to the overall } \\
\text { attention of the } \\
\text { students and the } \\
\text { eye contact } \\
\text { frequency }\end{array}$ \\
\hline
\end{tabular}

\subsection{Social Skills}

Children with ASD often are not able to present high levels of social awareness. This is the greatest reason for their difficulty in creating and maintaining relationships in various environments e.g. classroom (Wainer \& Ingersoll, 2011). The following section presents two studies that use AR for teaching skills to individuals with ASD. Escobedo, Nguyen et al (2012) investigated the use of a mobile assistive application, MOSOCO, to help children with ASD practice their social skills, to a total of 15 children (3 with ASD and 12 typically developed), between 8 and 11 years old. MOSOCO utilized AR and other visual supports for facilitating students in practicing their social skills in real-life conditions via guiding them through the six basic social skills from the Social Compass Curriculum. The application runs on a handheld device, with build on camera, android software and wireless connection to a server. It uses the camera for augmenting real-life social situation with visual support. Finally, it provides feedback to the user informing him for possible interaction partners, step-by-step guidance for communicating and improving their social skills and a reward system.

Outcomes of the study were measured from video recordings, physical observation and weekly interviews. Overall, students were positively versed towards MOSOCO, since they found it useful, fun and helpful. Furthermore, typically developed children were supported in learning how to be more understanding with children that have ASD and also developed new strategies for communicating with them. The participants that suffer from ASD displayed significant improvements: in the total time engaged in a social misstep with a 76.52\% reduction (pre: $\mathrm{t}=3 \mathrm{~min} 33 \mathrm{sec}$, using MOSOCO: $\mathrm{t}=50 \mathrm{sec}$ ), in demonstration of typical ASD behavioral issues during an interaction (pre: 50, using MOSOCO: 1 ) and in time spent not interacting with others (pre: 27 , using MOSOCO: 7) (Escobedo et al., 2012).

Given the fact that MOSOCO reduced social missteps by $56 \%$ and behavioral issues by $98 \%$, it may be said that using AR in real-life social situations has an impact on students' social groups. Nevertheless, the study is limited, due to the small number of participants, and this is why results cannot be extended to larger populations until they can be confirmed by further research. However, the fact that participants with ASD presented some progress in all the examined fields can be seen as a beginning for the future of AR applications in helping individuals with ASD.

Bhatt, De Leon and Al Jumaily (2014), developed two AR games for enhancing social interaction and hand-eye coordination to children with ASD. These games are based on colour detection and colour and motion tracking and are played with repetitive moves and instructions. The two games are: a) Emotions Game and b) Happy Minion Game and can be played with real objects from user's background. Emotion's Game allows a player to create expressions on a blank face by dragging and dropping features, according to the situation that the instructor has presented. Users can play the game with any device that has build-on or external camera. Players also, they have the possibility to choose, as a marker, any object from their background which afterwards the game detects and registers based on its colour. Finally the game provides instructors a feedback of the level of the player and the potential improvement. The second game, Happy Minion Game, is for training ASD children on hand-eye coordination. It was developed with Greenock Animation Platform and, like the first one it can be played on any device with camera. Players have to move their hand in order to control the cartoon character and hit bananas. According to their performance cartoon's face gets happy or sad. 6 
A usability study was performed with 4 typically develop children aged between 10-15. Participants' after playing the games had to answer a questionnaire. Results shown that they found the games easy to follow and they reported no difficulties in understanding the instructions or the language (simple English), while older participants also stated that using objects from their environment was exciting. Also, especially the Happy Minion Game was found to be more engaging since there was a score tracking system. But, since the study group was parted from typically developed children, they found both games repetitive (Bhatt, De Leon, \& AlJumaily, 2014).

Results from the study indicate that the games have the potential to improve the social skills and handeye coordination of children but further research is mandatory in order to extend these assumptions to children with ASD. Also research should be done for improving the quality of the games and also both games have to be tested on children that have been diagnosed with ASD. Because the presented studies are exploratory in nature it is not possible to draw definite conclusions about the effectiveness of AR in improving the social skills of individuals with ASD and how they will be able to apply these skills in everyday life. Also, since social skills demand interaction with other people it is not easy for a technology to replace this demand. Finally, more research on AR intervention should be done, in cooperation with other programs, in order to better evaluate its effectiveness in improving the social skills of people with ASD.

\subsection{Emotion Recognition}

ASD is characterized by difficulty in understanding the emotional and mental state of others (Benson, 2016). Emotion recognition training is something that can help people with ASD in improving their skills in this area. This section is parted from three articles that propose the use of AR for this particular purpose. Chen, Lee and Lin (2015) investigated the use of an AR-based self-facial model (ARSFM) in teaching emotional recognition skills to adolescents with ASD. This program was designed with the use of an augmented mirror through which users' could see themselves with 3-D visual expressions, and choose according to the described story. Three children with ASD took part in the study, ranged from 10 to 13 years old. A therapist conducted the sessions and helped participants throughout the three phases of the experiment (baseline, intervention and follow up phase) in the baseline phase therapists asked the participants to choose of the 6 basic emotional expressions that describes better the presented scenarios. During the intervention phase the ARSFM system was implemented and the follow up phase was conducted 2 weeks after the previous phase in order to determine whether participants were benefited from the application.

Results from the study show that this learning system can facilitate the emotional recognition teaching of children with ASD. Furthermore, the correct assessment rates of all participants raised significantly, more than $60 \%$ in intervention phase and remained $50 \%$ in the follow up phase compared with baseline phase. Also the ARSFM system helped participants in staying focused during therapy and according to their parents it improved their social skills and enabled them to express and understand feelings easier (Chen, Lee, \& Lin, 2015). Nonetheless, further research is required with involving more participants, since the initial one had only 3 , for generalizing the results. The same research team in 2016 created and AR video-modeling storybook (ARVMS) for improving the perception of emotions and facial expressions to children suffering from ASD. This program utilized 20 videos that portrayed aspects of everyday life, a storybook related to the videos and AR for combining these two (by scanning with a device the story book access is permitted to the videos). Vuforia platform was used for creating the AR interface. Consistent reinforcement and help were provided throughout the experiment from therapists that also evaluated the performance of each individual and asked questions related to the emotions and facial expressions presented in each video. In total 6 children with ASD, ranging from ages 11 to 13, took part in the study. They followed the three phases of the program and afterwards the following results were extracted. The first phase, baseline, was used for collecting data related to the participants, the second one, intervention, was the phase were 7 the ARVMS model was implemented and the last phase of maintenance which took place 4 weeks after the second, was for assessing the performance of the participants. During and after the intervention phase participants presented significant raising in their scores in understanding the emotions presented in the storybook (baseline: 30-53-5\%, intervention: 93.5-98.57\%, maintenance: 86.66-94.28\%). (Chen, Lee, \& Lin, 2016) These results indicate that the ARVMS learning system can be proved useful for teaching individuals with ASD how to recognize and understand emotions and facial expressions of other people. AR made teaching students with ASD more interactive, interesting and efficient that traditional methods, but it should be further tested in a greater scale with more participants of all age groups for having more reliable results. Brandao, Vuhna et al. (2015), developed an AR GameBook for assisting children with ASD in recognizing and acquiring emotions. This application was based on a book-style serious game that facilitates children in interacting with other people and practicing their social skills. The GameBook presents the story of Tobias, as he visits the zoo. It describes five scenarios that enable students to interact with the introduced characters and learn facial expressions, which afterwards have to use according to each situation. The application can be played by any mobile device with camera and with access to an online server and 
provide players the ability to read the story or listen it. At the end of each chapter there is a simple quiz related to the emotions described in the chapter. Finally, after finishing all five chapters users have the opportunity to download the book in PDF version and receive a memory game with all the expressions presented in the book. Unfortunately, the authors' team has not yet conducted any studies for the usability of the application in real conditions, something that they have already pointed out in their paper (Brandão, Cunha, Vasconcelos, Carvalho, \& Soares, 2015). AR applications can be effective for familiarizing children with ASD syndromes with emotions, but it is uncertain whether they will be able to incorporate this knowledge in real life. It may be possible that an interactive technology, like AR, is not appropriate for individuals with ASD emotion recognition teaching (Baron-Cohen, 2000). Results from the abovementioned studies though indicate that students with ASD can be benefited from the use of AR in this field. Nevertheless, additional research is something necessary in order to fully understand the exact effects of AR in teaching emotion recognition to people with ASD.

\subsection{Other Fields}

Apart from social skills and emotion recognition, people with ASD syndromes present difficulties in many other aspects of their life, like acquiring skills, playing and also in education (Benson, 2016; Escobedo et al., 2012). In this section three articles are presented related to the use of AR for facilitating children with ASD for problems like the abovementioned. In 2012, Casas, Herrera, Coma and Fernadez created an AR system for teaching key developmental abilities to individuals with ASD. The system was designed in the form of an augmented mirror, where users can see themselves augmented with virtual objects. The main purpose of the application was to help people with ASD to develop their self-awareness and also to improve their critical abilities. In order to do so, researchers use a Pictogram Room along with Kinect and combined them with a PC, a projection system and speakers. The system has two roles, an educator and a student. Educators select activities that the child should perform and provides instructions and explanations. Both roles are presented in the augmented world by virtual puppets along with virtual objects, according to the activity. For evaluating the application, researchers undertook two tests, one with typically developed children and one with children that have been diagnosed with ASD. For the first experiment 22 children participated between 3 to 4 years old. They performed 4 activities related to moving and touching and then the educators noted their performance. All participants from this group were able to perform the activities, although some of them needed more explanations. The second group consisted of 5 children with ASD. The majority of them, 3 out of 5, managed to calibrate (stay still for few seconds) and use the system, while the other 2 presented difficulties (Casas, Herrera, Coma, \& Fernández, 2012). 8 Overall, the few findings from these initial studies suggest that this Kinect-based AR system can be used from children with ASD. However, lack of a bigger scale research and more detailed results make mandatory the conduction of more studies with greater number of participants. Bai, Blackwell and Coulouris (2013), proposed an AR system for encouraging pretend play to children with ASD. This system was designed based on the metaphor of a mirrored view of reality enriched with AR augmentations. The chosen play theme was vehicles, since children with ASD tend to present great interest in this field. Also, it compromises three play scenes, each one, integrated three augmentations for encouraging more complex play behaviors (e.g. spontaneous engagement, develop of more complex play ideas and mixing non-augmented toy to the play scenarios). The prototype was tested via a pilot study with 4 normally developed children, aged from 4 to 5 , and confirmed that the hand-eye coordination in this age is sufficiently developed for using this system. Afterwards, the main study was conducted, with 12 children diagnosed with ASD syndromes, from 4 to 7 years old. After getting familiarized with the system, participants used the program and answered a questionnaire related to its use. Also, participants' parents were asked to complete a questionnaire in order to collect more feedback for evaluating the application. The main results showed that the frequency of pretend play, while using the system, was higher, while constructive play was more frequent in the non-AR condition. The same results applied for the play duration. Parents stated that were more engaged and showed more enjoyment when using the AR system. Finally, the mean percentage of total relevant actions was higher when AR was used $(t$ test: $t(9)=2.84$, $\mathrm{p}<0.05$ ) (Bai, Blackwell, \& Coulouris, 2013). The above presented results suggest that there is a positive effect in the duration of pretend play with the use of AR. The nature of AR can facilitate children with ASD to focus and carry on with pretend play actions, since it is a silence visual technology. It must be noted though that further improvements are needed for generalizing these results beyond the exploratory level. Tobar-Muñoz, Baldiris and Fabrefat, in 2014, developed an AR-enriched videogame for logical math skills that addresses students with special needs. The game is parted from two mini-games, one for fostering pairing (Raining Gremlins) and one for ordering (The Gremvolution). For the observation scenario, apart from the web version, the team constructed a standalone version with a record system for collecting users' data. The study 4 typically developed students and 16 students with special needs were used as sample, two of them with ASD syndromes (Autism and Asperger syndrome). After dividing them in two groups, typically developed and special needs, and providing them with a printed AR-marker the observation begun. Results indicate that students with special 
needs needed more time than the typically developed but on the other hand their scores and performance was similar. Researchers concluded that their application achieves the inclusion of all children into the educational procedure and that since all students achieved their goals they felt motivated in participating (Tobar, Fabregat, \& Baldiris, 2014). Also, Almeida da Silva, Fernandes and Grohmann (2015), introduces STAR, an AR application that enables therapist in intervention sessions and assists parents in joining and participating in their child's intervention. STAR allows the creation of activities that are suitable for each individual child, according to the degree of ASD and other parameters. The project uses communication symbol cards, which are already familiar to the child and are enriched with 3D models and animations. For evaluating the application, the research team conducted a study during speech/language training intervention sessions. In the study 4 students with ASD took part aged from 6-10 years old. After 13 sessions, results indicate that students remained focus during the various activities for a longer period of time, managed to complete them correctly, after the first session they asked to make use of the program and finally they acquired new vocabulary. On the other hand though there were issues related to the overall attention of the students and the eye contact frequency which indicate that a balance must be achieved between different types interventions (da Silva, Fernandes, \& Grohmann, 2015). 9 Finally, Escobedo and Tentori (2014), in their article presented an 8 week study of MOBIS, an AR application for teachers of students with ASD that enables the digital annotation of information onto physical objects. This augmentation can be scribbles, audio, text or figures. Also MOBIS records students' activities in order to enable teachers to create detailed portfolios without losing their focus, by keeping notes, during therapy. For this study 7 teachers and 14 students were registered as participants. Students were diagnosed with ASD and were between 3 and 7 years old. During the 8 weeks of the program students and teachers participated in three phases: a) pre-deployment of MOBIS were students participated in a standard therapy session, b) deployment of MOBIS were the application was incorporated in the therapy session and c) post-deployment of MOBIS were participants returned to the initial therapy sessions. Data for the evaluation were collected via video recordings and personal interviews with the teachers. Results showed a positive impact of MOBIS on the workload and burden of teachers, since it reduced the time they spend for giving prompts (before: 18.28, after: 17.54), taking notes (before: 00:01:02, after: 00:00:56) and also they were able to teach more than one students per session (Escobedo \& Tentori, 2014). Concluding, MOBIS can be proved a useful application that facilitates teachers during therapy session and improves the efficiency of these therapies. Future research though should be focused in how this application can the generalization of these skills in real conditions. Results from these 5 studies suggest that AR applications may be used effectively in teaching students with ASD different skills and facilitate their teachers by reducing their workload an enabling them to be more focused on their students. However, it is more than clear that research in this field is still in its infancy and further research should be done. Finally, although these articles propose innovative ideas, it is unknown whether they can really lead to the application of the learned skills in everyday life.

\subsection{Program Development}

\section{Recommendations}

The reviewed articles examined the application of AR technology to intervention programs for children with ASD. These programs used AR for introducing various fields like social skills, emotion recognition, pretend play, self-awareness etc. to students with ASD. They varied in the application, delivery and instructional concept, but on the other hand they all included the use of technology tools like computers, handheld devices, cameras and other features that can attract the interest of children suffering from ASD syndromes during therapy sessions (Escobedo et al., 2012; Rayner, Denholm, \& Sigafoos, 2009). Future research related to the development of AR applications should work on finding ways of motivating students. One way of achieving these results is by making technological tools adaptable to students, since at the moment students are called to adapt themselves to each method and tool. AR is a technology that enables this process, something very important, since people with ASD need intervention programs that can be transformed according to their needs. Programs and applications presented a different level of support and/or feedback that they provided to users and their therapists. Also, usually users require different levels and types of feedback according to their condition, age and the type of skills they intend to practice. All the presented programs and applications included some level of support for users, like feedback, but this reinforcement was different for each case, according to the targeted goals. The development of future programs with AR technology should try to incorporate more techniques for teaching children with ASD rather than reinforcement and feedback (Wainer \& Ingersoll, 2011), like Floortime, or Difference Relationship Model (DIR) where the teacher helps the child by meeting him at his developmental level and building on his strengths, usually during play time (ICDL). Also, another technique is to let the children "feel" by using their sense of touch. This sense is the most important, especially for nonverbal children, and if used properly it can help them I acquiring language and improve their communication (Grandin, 2002). 10 Another aspect of the programs' development that should be discussed is the exclusive use of computers for teaching students. Most of the applications used only computers for achieving their goals, 
while only few of them incorporated external material, like books and physical objects. Also, for concepts were physical contact is needed (e.g. social skills practice) only one of the examined programs required interaction with others. Researchers should consider the nature of the skills that each application addresses in order to decide the utilization of physical objects or other people for improving the efficiency of the intervention. For people with ASD, for example, the sense of touch is something really important and by using only equipment that mainly targets the sense of hearing or seeing a great limit is created. Physical objects play a really important role in special education and that should not be forgotten when someone creates applications for intervention (Grandin, 2002). Technological tools, like AR, can be used along with other features in order to achieve the best results (Da Silva et al., 2015). Finally, all the presented programs were created for teaching skills related to social behaviors, apart from few programs that were created for enabling teachers to reduce their workload (e.g. keeping notes during sessions) and get more focused to the child/children, helping parents in joining intervention sessions or teaching math skills. It is clear that the enhancement of such skills is important, especially for people that have been diagnosed with a disorder that causes issues in communication ability, but the development of other abilities (e.g. language skills, self-advocacy) is also necessary too.

\subsection{Program Evaluation}

After reviewing the applications that use AR for intervention in several concepts for children with ASD, it can be proposed that AR programs can potentially teach skills to a number of people with ASD. Nevertheless, data obtained from these studies cannot still be used for consolidating this standpoint, since researches are limited in the number of participants. The majority of the articles presented in this paper contained small scale studies that do not examine deeply the usability of the applications. Also, all articles presented results that show positive feedback related the programs, both from parents and children. All the abovementioned reasons make it extremely difficult to formulate solid results related to the use of such programs. Some of the limitations that were discovered to all studies are the small sample sizes that varied from 0 to 27 participants and the homogeneity in participants' age and diagnosis. Theses can lead to doubts related to the adoption and the expansion of the results to other groups. It is essential that future studies make use of more participants for generalizing the effectiveness of the applications in order to have a global impact. Also, the type of disability of each participant is something that researchers should take in to account when designing applications in the future, since as each person has different abilities and skills, people with ASD present different characteristics. This is why future applications should give the ability to therapists to adjust the program according the needs of each student. Concluding, studying the application of a technology like AR to the therapy sessions of individuals with ASD is something that should be treated with care. AR is a new technology that has not yet been implemented in classic education, hence it can be difficult to examine its effectiveness in special education. Intervention programs that use AR should not be examined only for the effectiveness of the technology itself, but for the effectiveness of the intervention methods along with AR. Future research should keep in mind that applications are effective only if both technology and intervention methods are used properly and this is why they both should be examined separately and combined. Only then results will be valid and real steps towards the improvement of everyday life of people with ASD will be made.

\subsection{Further Research}

After examining the abovementioned articles and finding the gaps that exist in the research field, there are a few issues that emerge and will be the focus of future research efforts of our team. These issues are:

The creation of an AR application for people with ASD that may combine a variety of teaching methods like feedback, reinforcement, DIR model etc. and will be based on models that are suitable for students with ASD (eg. ABA - Lovaas, TEACCH, PECS, DIR/Floortime etc.).

Design of the application in a way that enables the teacher/therapist to adapt it to users' needs, providing a greater degree of personalization.

Combination of AR with physical objects and/or other people to maximize results and avoid alienation.

Testing of application in a research with a significant sample of individuals with ASD for drawing conclusions about its effectiveness.

\section{Conclusions}

In this paper a literature review was conducted. In total 10 articles, related to the use of AR for intervention to people with ASD syndromes, were assessed and divided in 3 categories according to their content. These categories were: social skills, emotion recognition and other fields. We analyzed the purposes, limitations and effectiveness of AR in intervention sessions. Also, the quality and results of the evaluation methods were analyzed (research method, sample etc). A short summary of the main findings is presented below.

$\square$ The number of studies about AR and the education of people with ASD is still in its beginning. 
Social skills and Emotion Recognition are the fields were AR has been applied the most.

The majority of the studies focuses on children.

The use of marker-based AR is dominant since it is cheaper and also easier for therapists to handle since location-based AR mostly requires exploration of the external environment, something that can be noted as inconvenient while teaching students with ASD.

$\square$ The main advantages that AR offered are: motivation, interactivity and ease of operation.

The main limitations that were noted are: small research samples (3-27 participants) that do not allow the globalization of results, some applications were not tested with children that have ASD and of course the small number of studies.

Future research should focus on examining in more detail whether applying AR in intervention of people with ASD is something beneficial and also to document this theory with extended research for clarifying which aspects are the most efficient and helpful and which method may lead to better results. The use of AR, a new and innovative technology, in therapy of children with ASD can be seen as an effective, yet immature method. After considering the fact that the application of AR in the education of typically developed children is still in its infancy, it is expected that the amount of research articles for its application to intervention programs for ASD is small. For all that, future research and also education systems and health agencies should become more effective and ethical awareness towards social groups that require special treatment.

\section{References}

[1] Autism Society about Autism. Retrieved 27/8/2016, from www.autism- society.org/about-autism/

[2] Bai, Z., Blackwell, A. F., \& Coulouris, G. (2013, 1-4 Oct. 2013). Through the looking glass: Pretend play for children with autism. Paper presented at the Mixed and Augmented Reality (ISMAR), 2013 IEEE International Symposium on.

[3] Baron-Cohen, S. (2000). Theory of mind and autism: A review International Review of Research in Mental Retardation (Vol. Volume 23, pp. 169-184): Academic Press.

[4] Benson, S. (2016). What Is Autism Spectrum Disorder?, from https://www.psychiatry.org/patients-families/autism/what-is-autismspectrum-disorder

[5] Bhatt, S. K., De Leon, N. I., \& Al-Jumaily, A. (2014). Augmented reality game therapy for children with autism spectrum disorder. International Journal on Smart Sensing \& Intelligent Systems, 7(2), 18.

[6] Brandão, J., Cunha, P., Vasconcelos, J., Carvalho, V., \& Soares, F. (2015). An Augmented Reality GameBook for Childrenwith Autism Spectrum Disorders. Paper presented at the The International Conference on E-Learning in the Workplace, New York, NY, USA. https://www.icelw.org/program/ICELW\%202015\%20Proceedings/ICELW2015/papers/Brandao_Cunha_et_al.pdf 12

[7] Casas, X., Herrera, G., Coma, I., \& Fernández, M. (2012). A Kinect-based Augmented Reality System for Individuals with Autism Spectrum Disorders. Paper presented at the GRAPP/IVAPP. pdfs.s3.amazonaws.com/bf22/c0a897a3d85d72a3dde6719b1ee21437a761.pdf

[8] Chen, C.-H., Lee, I. J., \& Lin, L.-Y. (2015). Augmented reality-based self-facial modeling to promote the emotional expression and social skills of adolescents with autism spectrum disorders. Research in Developmental Disabilities, 36(0), 396-403. doi: http://dx.doi.org/10.1016/j.ridd.2014.10.015

[9] Chen, C.-H., Lee, I. J., \& Lin, L.-Y. (2016). Augmented reality-based video-modeling storybook of nonverbal facial cues for children with autism spectrum disorder to improve their perceptions and judgments of facial expressions and emotions. Computers in Human Behavior, 55, Part A, 477-485. doi: http://dx.doi.org/10.1016/j.chb.2015.09.033

[10] Cuendet, S., Bonnard, Q., Do-Lenh, S., \& Dillenbourg, P. (2013). Designing augmented reality for the classroom. Computers \& Education, 68(0), 557-569. doi: http://dx.doi.org/10.1016/j.compedu.2013.02.015

[11] Da Silva, C. A., Fernandes, A. R., \& Grohmann, A. P. (2015). STAR: Speech Therapy with Augmented Reality for Children with Autism Spectrum Disorders. In J. Cordeiro, S. Hammoudi, L. Maciaszek, O. Camp \& J. Filipe (Eds.), Enterprise Information Systems: 16th International Conference, ICEIS 2014, Lisbon, Portugal, April 27-30, 2014, Revised Selected Papers (pp. 379-396). Cham: Springer International Publishing.

[12] Escobedo, L., Nguyen, D. H., Boyd, L., Hirano, S., Rangel, A., Garcia-Rosas, D., . . . Hayes, G. (2012). MOSOCO: a mobile assistive tool to support children with autism practicing social skills in real-life situations. Paper presented at the Proceedings of the SIGCHI Conference on Human Factors in Computing Systems, Austin, Texas, USA.

[13] Escobedo, L., \& Tentori, M. (2014). Mobile Augmented Reality to Support Teachers of Children with Autism. In R. Hervás, S. Lee, C. Nugent \& J. Bravo (Eds.), Ubiquitous Computing and Ambient Intelligence. Personalisation and User Adapted Services: 8th International Conference, UCAmI 2014, Belfast, UK, December 2-5, 2014. Proceedings (pp. 60-67). Cham: Springer International Publishing.

[14] Farr, W., Yuill, N., \& Hinske, S. (2012). An augmented toy and social interaction in children with autism. nternational Journal of Arts and Technology (IJART), 5. doi: http://dx.doi.org/10.1504/IJART.2012.046270

[15] Fonseca, D., Martí, N., Redondo, E., Navarro, I., \& Sánchez, A. (2014). Relationship between student profile, tool use, participation, and academic performance with the use of Augmented Reality technology for visualized architecture models. Computers in Human Behavior, 31(0), 434-445. doi: http://dx.doi.org/10.1016/j.chb.2013.03.006

[16] Grandin, T. (2002). Teaching Tips for Children and Adults with Autism. Retrieved 30/9/2016, from https://www.iidc.indiana.edu/pages/Teaching-Tips-for-Children-and-Adults-with-Autism

[17] ICDL. DIR and the DIR Floortime Approach. Retrieved 1/9/2016, from www.icdl.com/DIR

[18] Karamanoli, P., \& Tsinakos, A. A. (2015). Use of Augmented Reality in Terms of Creativity in School Learning. Paper presented at the Workshop of Making as a Pathway to Foster Joyful Engagement and Creativity in Learning (Make2Learn), Trondheim, Norway. http://ceur-ws.org/Vol-1450/paper7.pdf

[19] Krasny, L., Williams, B. J., Provencal, S., \& Ozonoff, S. (2003). Social skills interventions for the autism spectrum: essential ingredients and a model curriculum. Child and Adolescent Psychiatric Clinics, 12(1), 107-122. doi: 10.1016/S1056-4993(02)000512 
[20] Mintz, J. (2013). Additional key factors mediating the use of a mobile technology tool designed to develop social and life skills in children with Autism Spectrum Disorders: Evaluation of the 2nd HANDS prototype. Computers \& Education, 63, 17-27. doi: http://dx.doi.org/10.1016/j.compedu.2012.11.006

[21] Nincarean, D., Alia, M. B., Halim, N. D. A., \& Rahman, M. H. A. (2013). Mobile Augmented Reality: The Potential for Education. Procedia - Social and Behavioral Sciences, 103(0), 657-664. doi: http://dx.doi.org/10.1016/j.sbspro.2013.10.385

[22] Olney, M. F. (2000). Working with autism and other social-communication disorders. Journal of Rehabilitation, 66(4), 6.

[23] Prieto, L.-P., Wen, Y., Caballero, D., \& Dillenbourg, P. (2014). Review of Augmented Paper Systems in Education: An Orchestration Perspective. Educational Technology \& Society, 17(4). 13

[24] Rayner, C., Denholm, C., \& Sigafoos, J. (2009). Video-based intervention for individuals with autism: Key questions that remain unanswered. Research in Autism Spectrum Disorders, 3(2), 291-303. doi: http://dx.doi.org/10.1016/j.rasd.2008.09.001

[25] Roesner, F., Denning, T., Newell, B. C., Kohno, T., \& Calo, R. (2014). Augmented reality: hard problems of law and policy. Paper presented at the Proceedings of the 2014 ACM International Joint Conference on Pervasive and Ubiquitous Computing: Adjunct Publication, Seattle, Washington.

[26] Sood, R. (2012). Pro Android Augmented Reality Apress.

[27] Tobar, H. F., Fabregat, R., \& Baldiris, S. (2014). Using a Videogame with Augmented Reality for an Inclusive Logical Skills Learning Session. Paper presented at the 16th International Symposium on Computers in Education, La Rioja, España. https://www.researchgate.net/publication/268684267_Using_a_Videogame_with_Augmented_Reality_for_an_Inclusive_Logical_S kills_Learning_Session

[28] Tomi, A. B., \& Rambli, D. R. A. (2013). An Interactive Mobile Augmented Reality Magical Playbook: Learning Number with the Thirsty Crow. Procedia Computer Science, 25(0), 123-130. doi: http://dx.doi.org/10.1016/j.procs.2013.11.015

[29] Wainer, A. L., \& Ingersoll, B. R. (2011). The use of innovative computer technology for teaching social communication to individuals with autism spectrum disorders. Research in Autism Spectrum Disorders, 5(1), 96-107. doi: http://dx.doi.org/10.1016/j.rasd.2010.08.002

[30] Wing, L., \& Gould, J. (1979). Severe impairments of social interaction and associated abnormalities in children: Epidemiology and classification. Journal of Autism and Developmental Disorders, 9(1), 11-29. doi: 10.1007/bf01531288 